Electroconvulsive

\section{therapy: do the figures add up?}

We welcome the recent interest shown by the Mental Health Commission in electroconvulsive therapy (ECT). However, we are concerned at some of the resultant comments in the medical and general press regarding the perceived geographical variations between Irish mental health services in the rate of ECT administration.

All rates are calculated on the basis of a numerator divided by an appropriate denominator. Regarding ECT, the numerator is 'the number of patients prescribed electroconvulsive therapy' recorded in the 'statistical information required for visit of inspection' forwarded on an annual basis by mental health institutions to the Inspectorate of Mental Services. We note that this definition will include those inpatients completing a course of ECT that was commenced late the previous year.

Therefore, it is possible that a single course of ECT for an individual patient will be included in the calculation of the ECT rate for two consecutive years. Given that ECT is primarily used on an inpatient basis for the treatment of depressive illness, it seems reasonable to conclude that the most clinically relevant and appropriate denominator to use in calculating a rate for ECT administration is the number of patients with a diagnosis of depression admitted to individual psychiatric units.

We wish to draw the attention of our colleagues and the Mental Health Commission to our recent observations using data from Report of the Inspector of Mental Hospitals and Activities of Irish Psychiatric Services for the year 2002. Essentially, we used the data from these reports to calculate a rate of ECT administration for individual services provided there was appropriate contemporaneous information within the relevant reports. Our primary aim was to evaluate our own clinical practice in relation to that of our peers in the context of our auditing the high rate of ECT and administration attributed to our service in 2002.

Unfortunately, our findings question the integrity of these data and suggest that caution is advisable when using these data sources to comment on rates of ECT administration. For example, one hospital was reported in the Report of the Inspector of Mental Hospitals to have administrated ECT to 38 patients but the corresponding Activities of Irish Psychiatric Services indicated that only four patients with a depressive disorder (out of total of 33 admissions for the year) were admitted to this institution! The only possible interpretation of this conflicting data is that the numerator reported was the number of applications of ECT used. Therefore we excluded this institution from the rest of the analysis.

The rate of ECT prescribed as a percentage of inpatients admitted with a depressive disorder ranged from $0 \%$ $63.96 \%$ (Mean 11.69, Median 8.28, SD 12.2). Before one rushes to judgement regarding the apparent finding that two out of every three depressed patients received ECT in one psychiatric unit, we feel it is imperative to highlight our own experience.

On the basis of the official figures, the rate of ECT administration within the Waterford psychiatric services was $39.1 \%$. However, when our clinical records were audited by medical and nursing staff we noted that only 69 patients (not 144 as noted in the Report of the Inspector of Mental Hospitals 2002 were prescribed ECT. Hence, our rate of ECT administration was in reality $18.7 \%$ and would have been lower if we had excluded those individuals whose course of ECT commenced in 2001 and finished in 2002. Our sense is that this discrepancy arose because of difficulties in the interpretation and reporting of clinical data by administrative staff.

In summary, we believe that it is premature to draw definite conclusions regarding geographical variations in the rate of ECT administration based on currently available data sources. In future, if ECT administration rates are going to be used as some form of 'proxy' performance indicator it is essential that valid, reliable and appropriately resourced data collection systems are established and regularly audited.

Noel Sheppard, Consultant Psychiatrist, Gerard Clarke, Assistant Chief Nursing Officer, Stephen Browne, Consultant Psychiatrist, Department of Psychiatry, Waterford Regional Hospital, Dunmore Road,

Waterford, Ireland.

\section{Flying solo: single/ unmarried mothers and stigma in Ireland}

Ireland's history of its treatment of mothers of children conceived outside of marriage is poor, if not to say an affront to human dignity. Although there have been substantial economic and social developments in Ireland in recent years, as well as a gradual increase in the proportion of children born outside of marriage, negative attitudes towards these mothers are unfortunately still prevalent.

Terms such as single or unmarried mother are often used in a pejorative manner and come with an associated negative 'baggage'. It must be acknowledged therefore that the use of these terms in the health services serves to replicate and reinforce such stigma.

In order to stop perpetuating such injustice it is therefore incumbent upon us to adopt new terminology (if marital status is considered a necessary piece of information at all). A replacement phrase that should be considered, which is widely used for example in New Zealand, is term 'Solo mother'. This term conjures up positive images of independence (it has associations of flying solo, solo circumnavigation of the globe, and so forth).

Such terminological changes are not idle political correct- 
ness. A very real stigma is associated with such terms. Perhaps health professionals, who should after all be familiar with the negative impact of stigma and low self-esteem, need to take a lead in this field by banning such terms.

Frank Houghton, Health Geographer Department of Public Health, Mid-Western Health Board, Limerick, Ireland.

\section{Evolutionary theory in psychiatry and psychology}

Charles Darwin's birthday, February 12, was recently marked by 'Darwin Day' celebrations worldwide, serving to highlight the seminal contribution of his theory of evolution to modern science. However, the role of evolutionary theory in psychiatry and psychology remains contentious. RT Abed's editorial in support of evolutionary psychiatry, published in the British Journal of Psychiatry in 2000, was followed by a heated debate in the correspondence pages of that journal. ${ }^{\prime}$

Proponents argue that evolutionary psychiatry and psychology provide a cohesive and robust theoretical framework within which to study human emotions and behaviour, generating useful research questions and clinically meaningful results. They claim that evolutionary theories provide 'ultimate' explanations (why a trait or system exists) in contrast to the 'proximate' explanations (how a trait or system works) provided by the other neurosciences such as genetics and neurochemistry.

Evolutionary psychiatrists view psychiatric illnesses such as mood disorders, psychotic illnesses, anxiety disorders and phobias as accentuations or dysregulation of normal states which in themselves are adaptive responses to individual and group conflict or environmental threats. Such theories resonate with Carl Jung's ideas of the 'collective uncon- scious' and some proponents of evolutionary psychiatry such as Anthony Stevens have their backgrounds in Jungian analysis.

To use the example of phobias, evolutionary psychiatrists argue that, in the more hostile and dangerous environment of our ancestors, those who were avoidant of certain animals and insects had a reproductive advantage and passed their phobic genes on to subsequent generations. In the case of mood disorders, however, evolutionary psychiatrists put forward more complicated explanations, describing depression and mania as accentuations of normal and adaptive responses to losses and gains that affect the reproductive fitness of the individual. The depressive state, for example, may help facilitate adjustment to a loss or lead an individual to avoid (and therefore survive) a conflict they are likely to lose. ${ }^{2}$ In contrast to these 'ultimate' explanations, Abed describes the monoamine theory of depression as a 'proximate', reductionist and unsatisfactory one.

Critics of evolutionary psychology and psychiatry question its theoretical basis and clinical relevance. They argue that the untestable nature of its theories means that different and sometimes conflicting explanations for human behaviours can be accommodated in evolutionary psychology and psychiatry. Rose refers to the discipline as "little more than an untestable bunch of anecdotes based upon a priori ideological convictions'.

Ultimately, only time will tell whether evolutionary psychology and psychiatry are selected to survive from among a plethora of competing paradigms.

Henry O'Connell, Research fellow and lecturer in Old Age Psychiatry Mercer's Institute for Research on Ageing St James's Hospital, Dublin 8, Ireland.

References

1. Abed, RT. Psychiatry and Darwinism. Time to reconsider? Br J Psychiatry 2000; 177: 1-3.

2. Stevens A and Price J. Evolutionary Psychiatry: A New Beginning (2nd ed). London: Routledge, 2000.

3. Rose S and Lucas P. Evolutionary psychology revisited (letter). Br J Psychiatry 2001; 178: 573 .

\section{Textbook of clinical psychiatry}

\section{The American Psychiatric Publishing Textbook of clinical psychiatry. Fourth Ed. Hales RE, Yudofsky SC. Washington DC: American Psychiatric Publishing, 2003. 1,647 pages plus index.}

This classic textbook is a massive, encyclopedic tome that took me five months to read. It purports to adopt GL Engel's biopsychosocial model. In order to conserve space, 10 chap- ters were dropped from the preceding edition and DSM-IVTR accompanies the book as a CD-ROM.

The text is clinical rather than the usual mixture of basic science and bread-and-butter psychiatry. There are four parts to the book: theory and foundations (from genetics to neuropsychology); disorders (as per DSM-IV-TR); treatments (heavy on psychological therapies); and 'special clinical topics' (suicide, violence, women, old age, culture, law, and ethics).

The style is very American. This is reflected in the literature references, the legal discussion, a complete chapter on 